\title{
Application of Fly Ash and Slag Generated by Incineration of Municipal Solid Waste in Concrete
}

\author{
Cong Zeng, ${ }^{1}$ Yan Lyu $\left(\mathbb{D},{ }^{2}\right.$ Dehong Wang, ${ }^{1}$ Yanzhong Ju $\mathbb{D}^{\circ},{ }^{1}$ Xiaoyu Shang, ${ }^{1}$ and Luoke $\mathrm{Li}^{3}$ \\ ${ }^{1}$ School of Civil Engineering and Architecture, Northeast Electric Power University, Jilin 132012, China \\ ${ }^{2}$ School of Civil Engineering and Architecture, Changchun Sci-Tech University, Changchun 130600, China \\ ${ }^{3}$ School of Civil Engineering and Architecture, Kunming University of Science and Technology, Kunming 650500, China
}

Correspondence should be addressed to Yan Lyu; 805359994@qq.com

Received 29 December 2019; Accepted 31 March 2020; Published 22 April 2020

Academic Editor: Dora Foti

Copyright ( $\odot 2020$ Cong Zeng et al. This is an open access article distributed under the Creative Commons Attribution License, which permits unrestricted use, distribution, and reproduction in any medium, provided the original work is properly cited.

As landfill space for the disposal of products of municipal solid waste incineration (MSWI) such as fly ash and slag becomes increasingly scarce, a reduction of disposed material is urgently required. The method of using incineration products in concrete production is explored in this paper through a feasibility study of utilizing fly ash and slag to replace cement and coarse aggregate in appropriate proportions. Results show that C30 concrete optimum replacement rates of fly ash and slag are $30 \%$ and $20 \%$, which can meet the minimum strength requirement. The leaching concentrations of $\mathrm{Cu}, \mathrm{Zn}, \mathrm{Pb}, \mathrm{Cr}$, and $\mathrm{Cd}$ in MSWI concrete samples are determined to be less than the identification value of solid waste leaching toxicity. Based on scanning electron microscopy (SEM) and X-ray diffraction (XRD) analyses, MSWI fly ash has certain dispersion. The particle size of MSWI fly ash is determined to be close to that of the coal fly ash, and the surface morphology is irregular. The main components include $\mathrm{SiO}_{2}, \mathrm{CaCO}_{3}$, and $\mathrm{Ca}_{2} \mathrm{SiO}_{4}$, and they are similar to those present in the coal fly ash. The slag structure is loose as well as irregular, and its main component is $\mathrm{SiO}_{2}$. The $\mathrm{SiO}_{2}$ and $\mathrm{Al}_{2} \mathrm{O}_{3}$ in fly ash and slag participate in the hydration reaction of cement and can increase concrete strength. It is thus confirmed that fly ash and slag generated by waste incineration can be used to replace cement and coarse aggregate in appropriate proportions, and it is an effective method to solve the problem of scarcity of solid waste landfill space.

\section{Introduction}

Based on a 2018 survey, the total amount of solid waste in China reached 3215.9 million tons, with an annual growth rate of $4 \%$ [1]. Common methods of municipal solid waste disposal currently include sanitary landfill and incineration. As incineration produces a small volume of waste, it is most commonly used to address increasing municipal solid waste production [2]. The main products of incineration are slag and fly ash. As slag contains only a small amount of heavy metals, it is available for reuse as a secondary building material [3, 4]. However, fly ash has been classified as hazardous waste due to high content of heavy metals, so it must be treated before discharge. As landfill space for fly ash and slag became increasingly scarce, a method for recycling these materials is urgently required [5].
Industrial waste such as granulated blast-furnace slag (GGBFS) and coal fly ash are widely adopted as complementary cementitious materials. Municipal solid waste incineration (MSWI) fly ash shares similar characteristics to coal fly ash, including chemical composition and heat history $[6,7]$. One of the most common strategies for the management of MSWI fly ash residues has been treatment followed by landfill as its chemical composition requires proper stabilization before disposal. Stabilization methods include separation, solidification/stabilization, and thermal treatment [8]. Using MSWI fly ash as aggregate in concrete has been explored, with the performance of fly ash concrete determined to be similar to that of natural aggregate with the required strength [9-12]. Moreover, some scholars have used MSWI fly ash and slag to partially replace cement in concrete production, with results illustrating that these 
wastes display good pozzolanic behavior and can contribute to increase concrete strength [13-15]. It has also been determined that MSWI slag can be used as an artificial aggregate, a particle binder, and the aggregate of road base [16-19]. Some scholars have focused on the by-product safety of MSWI fly ash and slag. However, as adequate testing and quality standards to assess the pollution potential of wastes are unavailable, it has been difficult to obtain conclusions concerning environmental rationality. Further experiments are also required to investigate the environmental effect of introducing MSWI fly ash and slag into concrete [20-22].

Few studies have explored using fly ash to replace cement and slag instead of coarse aggregate in concrete. Therefore, the aim of this preliminary study is to explore the viability of MSWI fly ash and slag to replace cementitious materials and coarse aggregate. The research results provide the ideal replacement rate of MSWI fly ash and slag and also contribute to the sustainable development of the concrete industry.

\section{Materials and Methods}

2.1. Materials. The raw materials used in this study include cement, fine aggregate, coarse aggregate, MSWI fly ash, MSWI slag, water, and water reducer. The fly ash and slag were obtained from the MSWI plant in Jilin, China. The fineness modulus of the fly ash was 3.2 , with an accumulation density of $1420 \mathrm{~kg} / \mathrm{m}^{3}$ and moisture content of $16 \%$. The bulk density was $1201 \mathrm{~kg} / \mathrm{m}^{3}$, and the apparent density was $2307 \mathrm{~kg} / \mathrm{m}^{3}$. After 24 hours, the absorption rate of MSWI slag was $10 \%$, and the crushing index was $30 \%$. The P.O 42.5 general silicate cement was obtained from a cement factory in Jilin, China. The fine aggregate was natural river sand with a particle size of less than $5 \mathrm{~mm}$, apparent density of $2553 \mathrm{~kg} / \mathrm{m}^{3}$, packing density of $1715 \mathrm{~kg} / \mathrm{m}^{3}$, and fineness modulus of 2.5. The particle size of the coarse aggregate was $5-25 \mathrm{~mm}$, the apparent density was $2677 \mathrm{~kg} / \mathrm{m}^{3}$, and the packing density was $1501 \mathrm{~kg} / \mathrm{m}^{3}$. The water reducing agent used in the experiment was polycarboxylic acid water reducing agent with a water reduction rate of $30 \%$.

2.2. Compressive Strength Test. This test refers to "Design Rules of Ordinary Concrete Mixing Ratio" (JGJ 55-2011) [23]. A standard cube sample $(150 \mathrm{~mm} \times 150 \mathrm{~mm} \times 150 \mathrm{~mm})$ was made with the strength grade of $\mathrm{C} 30$, and the slump was $30-50 \mathrm{~mm}$. The natural coarse aggregate was replaced with slag using mass proportions of $10 \%, 20 \%, 30 \%$, and $40 \%$, respectively, while the cement was replaced with fly ash with the mass proportions of $10 \%, 20 \%, 30 \%$, and $40 \%$, respectively. The coagulation mixing ratio was designed with a water-cement ratio of 0.48 , and the density of water reducing agent was $1.1 \mathrm{~kg} / \mathrm{m}^{3}$. The specific mixing design is shown in Table 1. After curing for 28 days at the relative temperature of $20 \pm 2^{\circ} \mathrm{C}$ and the relative humidity of $95 \%$, the test sample was taken for testing. Before the compressive strength tests, the specimen was soaked in warm water for $20 \mathrm{~h}$, and the surface was cleaned. Then, the specimen was tested at
0.5-0.9 MPa/s uniform loading speed by using a press machine (Jinxi Mechanical, China). When the compressive strength reached the steady-state, the loading was stopped and the compressive strength was recorded.

2.3. Heavy Metal Leaching Test. The leaching concentration of heavy metals is an important indicator for the safety evaluation of the solidified body, and it can ensure that the product is nontoxic and harmless to the environment $[24,25]$. This test refers to "Standard of Solid Waste Leaching Toxicity Leaching Method Standard-Horizontal Oscillation Leaching Procedure" HJ557-2010, as stipulated by the Chinese National Standard [26]. The specific test steps are described as follows: concentrated sulfuric acid and nitric acid were added to the deionized water with a mass ratio of $2: 1$ to prepare the leaching solution with $\mathrm{pH}$ of 3,5 , and 7 . The samples were dried at $50^{\circ} \mathrm{C}$ before grinding; then, $10 \mathrm{~g}$ of the sample with a particle size of $<9.5 \mathrm{~mm}$ was placed in a $1 \mathrm{~L}$ Erlenmeyer flask, and $200 \mathrm{ml}$ of leaching solution was added (liquid-solid ratio was $20: 1$ ). The sample was then fixed on the reciprocating horizontal oscillating machine, oscillated for $24 \mathrm{~h}$ at $110 \pm 5 \mathrm{RPM}$, and then left to stand for $16 \mathrm{~h}$. The clarified filtrate was obtained by suction filtration with the microporous membrane of $0.45 \mathrm{um}$, and the content of heavy metals in the leaching solution was determined by atomic absorption spectrometry.

2.4. Integrated Characterization. A scanning electron microscope (SEM) was used to observe the microscopic morphology of the materials, and X-ray diffraction (XRD) was used to detect the composition of the samples [27]. Analyzing the microstructure and composition of fly ash and slag provides increased understanding of the reaction mechanism of both materials in concrete and the influential factors of concrete strength.

\section{Results and Discussions}

3.1. Compressive Strength of Mixed Concrete. The failure process and mode of concrete mixed with fly ash and slag are found to be consistent with ordinary concrete. The failure process generally starts at the bond between the coarse aggregate and cement gel, especially the interface between the flake and cement gel, which is the main failure area in slag aggregate. For different fly ash substitution rates, the strength test results with unchanged slag substitution rate are shown in Figure 1(a). The results show that the compressive strength first increases and then decreases with increasing fly ash replacement rate, while the slag replacement rate is unchanged. When the fly ash and slag replacement rates are $10 \%$, the maximum strength can reach $53 \mathrm{MPa}$. The fly ash can fill the gap between different particle sizes, creating a more compacted concrete structure, while the microaggregate formation can also significantly enhance slurry hardness. Studies indicated that the ash plays an important role in achieving a good compressive strength [28]. In addition, the concrete uniformity is improved, and the fly ash particles are well dispersed in the cement slurry 
TABle 1: Concrete mix ratio design.

\begin{tabular}{|c|c|c|c|c|c|c|c|c|c|}
\hline \multicolumn{3}{|c|}{ Replacement (\%) } & \multicolumn{7}{|c|}{ Amount of material $\left(\mathrm{kg} / \mathrm{m}^{3}\right)$} \\
\hline Group & Fly ash & Slag & Cement & Fly ash & Slag & Coarse aggregate & Fine aggregate & Water & Superplasticizer \\
\hline B0C0 & 0 & 0 & 375 & 0 & 0 & 1227 & 638 & 180 & 1.1 \\
\hline B0C10 & 10 & 0 & 333 & 37 & 0 & 1227 & 638 & 180 & 1.1 \\
\hline B0C20 & 20 & 0 & 296 & 74 & 0 & 1227 & 638 & 180 & 1.1 \\
\hline B0С30 & 30 & 0 & 259 & 111 & 0 & 1227 & 638 & 180 & 1.1 \\
\hline B0C40 & 40 & 0 & 225 & 150 & 0 & 1227 & 638 & 180 & 1.1 \\
\hline $\mathrm{B} 10 \mathrm{C} 0$ & 0 & 10 & 375 & 0 & 122 & 1104 & 638 & 180 & 1.1 \\
\hline $\mathrm{B} 10 \mathrm{C} 10$ & 10 & 10 & 333 & 37 & 122 & 1104 & 638 & 180 & 1.1 \\
\hline B10C20 & 20 & 10 & 296 & 74 & 122 & 1104 & 638 & 180 & 1.1 \\
\hline B10C 30 & 30 & 10 & 259 & 111 & 122 & 1104 & 638 & 180 & 1.1 \\
\hline B10C40 & 40 & 10 & 225 & 150 & 122 & 1104 & 638 & 180 & 1.1 \\
\hline B20C0 & 0 & 20 & 375 & 0 & 242 & 982 & 638 & 180 & 1.1 \\
\hline B20C10 & 10 & 20 & 333 & 37 & 242 & 982 & 638 & 180 & 1.1 \\
\hline B20C20 & 20 & 20 & 296 & 74 & 242 & 982 & 638 & 180 & 1.1 \\
\hline B20C30 & 30 & 20 & 259 & 111 & 242 & 982 & 638 & 180 & 1.1 \\
\hline B20C40 & 40 & 20 & 225 & 150 & 242 & 982 & 638 & 180 & 1.1 \\
\hline B30C0 & 0 & 30 & 375 & 0 & 364 & 848 & 638 & 180 & 1.1 \\
\hline B30C10 & 10 & 30 & 333 & 37 & 364 & 848 & 638 & 180 & 1.1 \\
\hline B30C 20 & 20 & 30 & 296 & 74 & 364 & 848 & 638 & 180 & 1.1 \\
\hline B30C30 & 30 & 30 & 259 & 111 & 364 & 848 & 638 & 180 & 1.1 \\
\hline B30C40 & 40 & 30 & 225 & 150 & 364 & 848 & 638 & 180 & 1.1 \\
\hline B40C0 & 0 & 40 & 375 & 0 & 491 & 736 & 638 & 180 & 1.1 \\
\hline B40C10 & 10 & 40 & 333 & 37 & 491 & 736 & 638 & 180 & 1.1 \\
\hline B40C20 & 20 & 40 & 296 & 74 & 491 & 736 & 638 & 180 & 1.1 \\
\hline B40C 30 & 30 & 40 & 259 & 111 & 491 & 736 & 638 & 180 & 1.1 \\
\hline B40C40 & 40 & 40 & 225 & 150 & 491 & 736 & 638 & 180 & 1.1 \\
\hline
\end{tabular}

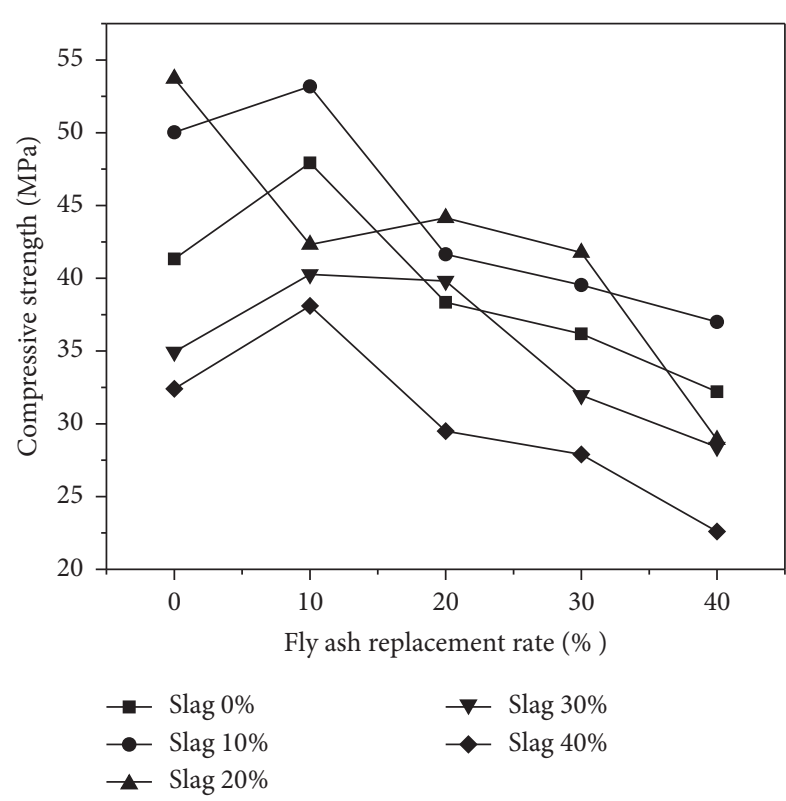

(a)

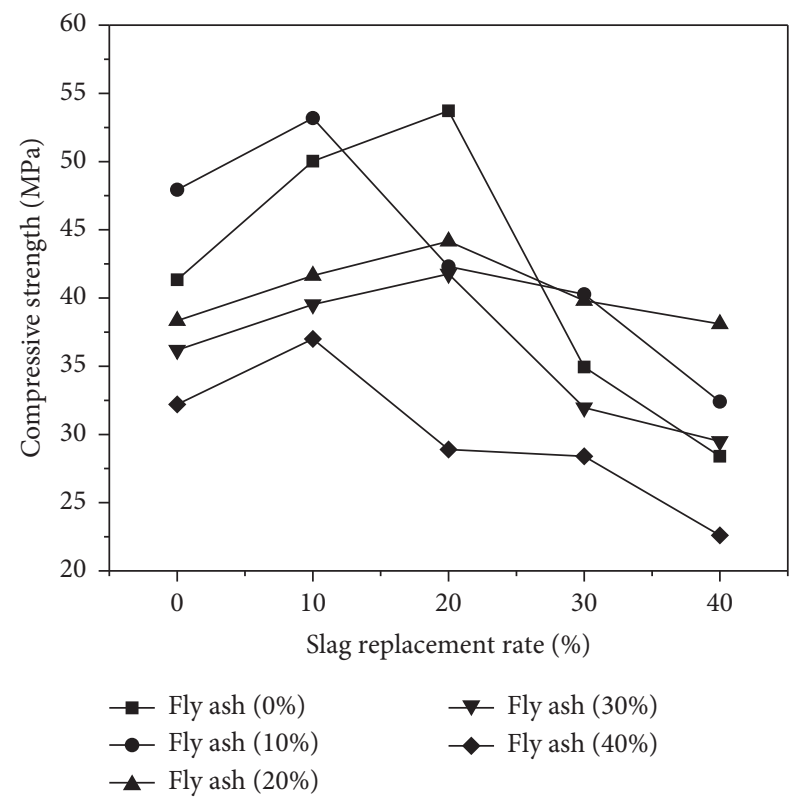

(b)

FIGURE 1: Strength of the sample mixed at (a) unchanged slag substitution rate under different fly ash substitution rates and (b) unchanged fly ash substitution rate under different slag substitution rates.

and can fill and refine the capillary pores in the concrete [29]. As the fly ash content increases, the compressive strength of the concrete gradually decreases. Based on the above analyses, the concrete strength mainly arises from the cementitious material generated after cement hydration. Once fly ash replaces cement, decreasing cement dosage can cause 
a corresponding decrease in the cementitious material after hydration. Although the fly ash can produce a certain amount of cementitious material, it is much less than the substitute cement. Therefore, the reduction of concrete strength is inevitable.

For different slag substitution rates, the strength of the sample mixed with unchanged fly ash substitution rate is shown in Figure 1(b). The fly ash replacement rates are $0 \%$, $20 \%$, and $30 \%$, with the maximum concrete strength appearing when the slag replacement rate reaches $20 \%$. With the fly ash replacement rate of $10 \%$ and $40 \%$, the maximum strength appears with the slag replacement rate of $10 \%$. The aggregate grade-paired concrete mechanical properties and the void ratio of sand and gravel aggregate have a significant influence on concrete performance. With a decreasing void ratio, the working performance and the mechanical properties of concrete can increase. When the slag replacement rate is $20 \%$, a superior gradation is formed between ordinary crushed stone aggregate and slag aggregate, which can promote the concrete strength. Meanwhile, the high replacement rate in slag can result in a weak binder interface between the cement and fly ash.

The high slag crushing index of coarse aggregate can result in a limit slag content (20\%), and the concrete strength can decrease with increasing slag rate. The lowest concrete strength of less than $30 \mathrm{Mpa}$ appears when the fly ash replacement rate is $40 \%$ and the slag replacement rate is $40 \%$. Thus, fly ash and slag cannot completely replace the cement and the coarse aggregate in concrete. According to the above results, the mixture ratio is determined as B20C30, which can meet the requirement of compressive strength and has the maximum replacement rate of fly ash as well as slag. The slag and fly ash substitution rates are $20 \%$ and $30 \%$, respectively.

3.2. Heavy Metal Leaching. Table 2 shows the leaching results of fly ash, slag, and coagulated heavy metals with the mixing ratio of B20C30. The leaching concentration of heavy metal $\mathrm{Cd}$ in fly ash is significantly higher than the identification standard for the leaching toxicity of solid waste. Although the leaching concentrations of heavy metals in concrete mixed with ash and slag do not exceed the limit, the leaching concentrations of heavy metals gradually increase as the acidity increases and the concentrations of $\mathrm{Cr}, \mathrm{Cd}$, and $\mathrm{Pb}$ gradually approach the present values. The leaching concentrations of heavy metals are significantly affected by $\mathrm{pH}$ value. As the acidity increases, the leaching concentrations of heavy metals gradually increase. Therefore, alkaline conditions are conducive to the solidification of heavy metals. As the concrete is alkaline, the heavy metals in fly ash and slag are solidified in hydration products by inclusion, substitution, or absorption. From the perspective of heavy metal hazards, it is feasible to apply fly ash and slag to concrete.

\subsection{Characterization Analyses}

3.3.1. SEM Analyses. Fly ash, slag, and concrete with mixture ratios of $\mathrm{B} 0 \mathrm{C} 0$ and $\mathrm{B} 20 \mathrm{C} 30$ microstructure were
TABLE 2: Fly ash, slag, and concrete leaching toxicity at different $\mathrm{pH}$ values $\left(\mathrm{mg} \cdot \mathrm{L}^{-1}\right)$.

\begin{tabular}{lcccccc}
\hline \multirow{3}{*}{ Fly ash } & $\mathrm{pH}$ & $\mathrm{Cu}$ & $\mathrm{Zn}$ & $\mathrm{Cr}$ & $\mathrm{Cd}$ & $\mathrm{Pb}$ \\
& 3 & 2.101 & 5.99 & 3.781 & 4.963 & 5.105 \\
& 5 & 1.473 & 5.02 & 2.201 & 2.393 & 1.323 \\
Slag & 7 & 0.412 & 0.459 & 0.576 & 1.213 & 0.714 \\
\hline \multirow{3}{*}{ B20C30 } & 3 & 0.316 & 6.33 & 1.212 & 0.305 & 3.135 \\
& 5 & 0.103 & 6.16 & 0.694 & 0.103 & 1.516 \\
Standard values & 7 & 0.025 & 0.791 & 0.037 & 0.042 & 0.91 \\
\hline
\end{tabular}

characterized using SEM. The fly ash microstructure is shown in Figure 2(a). As illustrated, the undisturbed fly ash phase has large voids, irregular shape, and strong dispersion, which can fill the concrete void and enhance concrete strength. The bottom slag microstructure is shown in Figure 2(b), in which the slag particles have a loose and porous structure. The individual particles are irregular in shape, with multiple edges and angles with rough surfaces. There are relatively few spherical particles, and the particle size is between coarse aggregate and fine aggregate. The coarse aggregate replacement in concrete can thus be observed to improve the aggregate gradation and enhance concrete strength.

As shown in Figure 3, after 28 days of curing, the concrete samples of B20C30 contain a high amount of spicules. The flake content of B0C0 is high, while the C-S-H gel content of $\mathrm{B} 20 \mathrm{C} 30$ concrete is also high with compact structure. The hydrated C-S-H gel is crisscrossed in the concrete system, and the tiny inert particles are distributed around the gel, indicating that the gelatin quantity can essentially reach the long-term strength requirement [30]. This may be attributed to the addition of fly ash and slag in B20C30 concrete, which can improve the concrete gradation. In addition, a large number of dispersed fine fly ash particles play the role of crystal nucleus and improve the compactness and the pore structure, and the fly ash and slag participate in the hydration reaction of concrete, which can also enhance the strength of B20C30.

3.3.2. XRD Analyses. The main components of fly ash, slag, and concrete crystallites were analyzed using XRD with a mix ratio of $\mathrm{B} 20 \mathrm{C} 30$. This analysis demonstrates the feasibility of replacing cement with fly ash and replacing coarse aggregate with slag. As shown in Figure 4, no heavy metal is detected in the crystalline phase as the content of heavy metals is low and most are contained by aluminosilicates or silicates or exist in the amorphous form. Additionally, the fly ash is generally crystallized as $2 \theta$ is equal to $11.6^{\circ}, 20.8^{\circ}, 24.9^{\circ}$, $29.4^{\circ}, 43.8^{\circ}, 49.9^{\circ}$, and $56.5^{\circ}$, with the main diffraction peak of $\mathrm{CaCO}_{3}$. As $2 \theta$ is equal to $26.6^{\circ}, 29.4^{\circ}, 38.5^{\circ}$, and $39.5^{\circ}$, the main diffraction peak is $\mathrm{SiO}_{2}$, and because the diffraction peak of $2 \theta$ is $32.7^{\circ}$, the main diffraction peak is $\mathrm{Ca}_{2}\left(\mathrm{SiO}_{4}\right)$. According to the XRD results, it can be seen that the main components of MSWI fly ash are similar to coal fly ash, and 


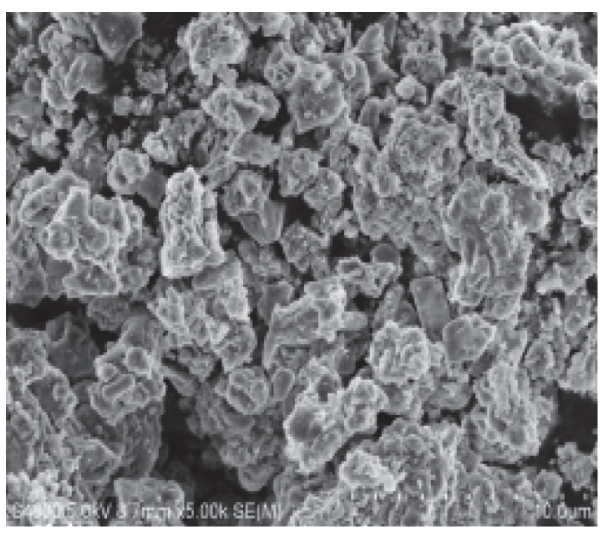

(a)

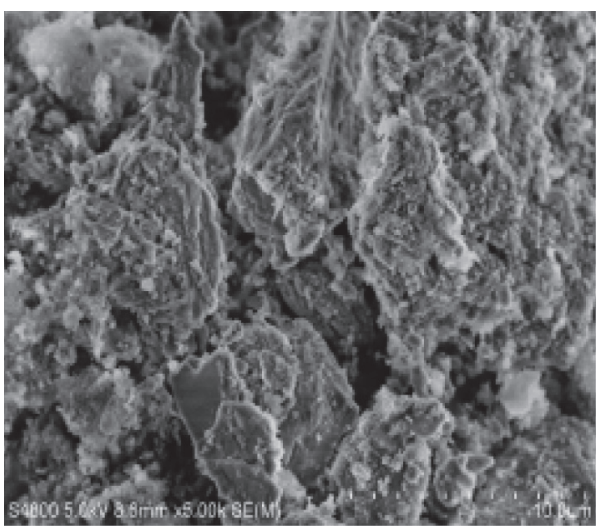

(b)

FIGURE 2: SEM scanning of (a) MSWI fly ash (magnification $\times 5000)$ and (b) MSWI slag (magnification $\times 5000)$.

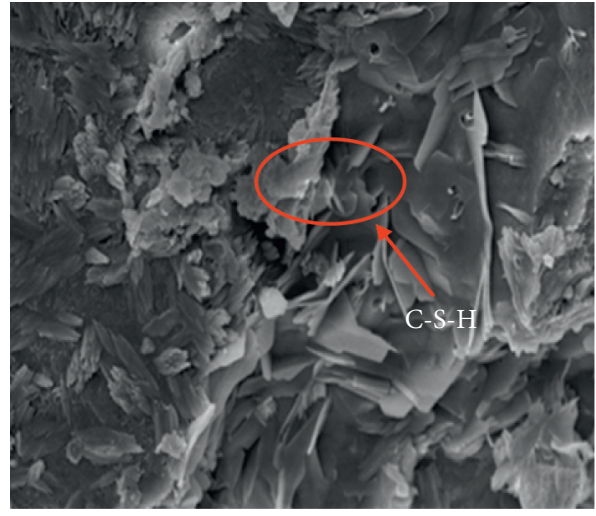

(a)

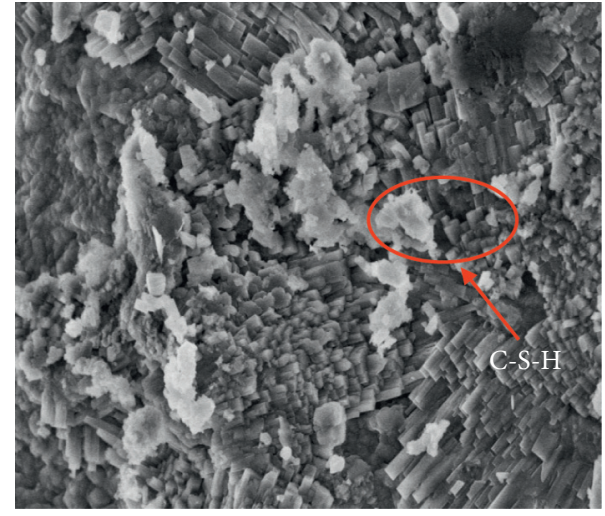

(b)

FIGURE 3: SEM images of concrete after 28 days of curing: (a) B0C0 (magnification $\times 5000$ ); (b) B20C30 (magnification $\times 5000$ ).

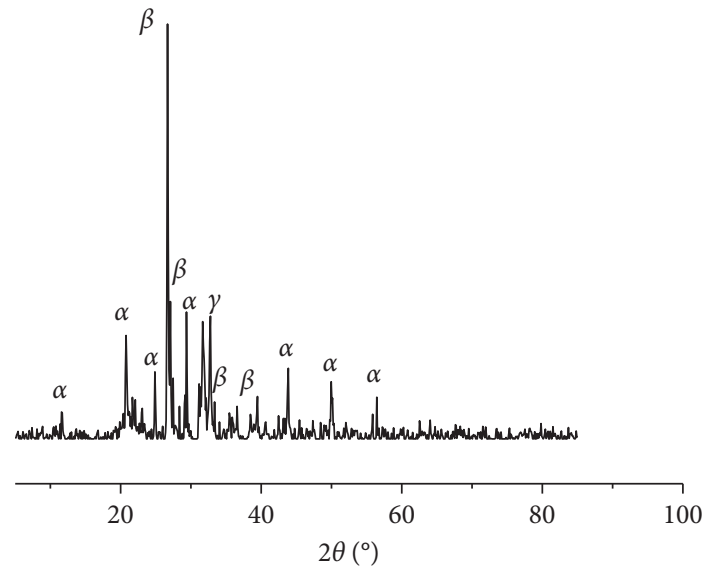

$\alpha-\mathrm{CaCO}_{3}$

$\beta-\mathrm{SiO}_{2}$ $\gamma-\mathrm{Ca}_{2}\left(\mathrm{SiO}_{4}\right)$

FIGURE 4: XRD image of MSWI fly ash.

the particles of fly ash are fine and spherical, which can enhance the workability of concrete. Therefore, MSWI fly ash can be used as a substitute for cement.

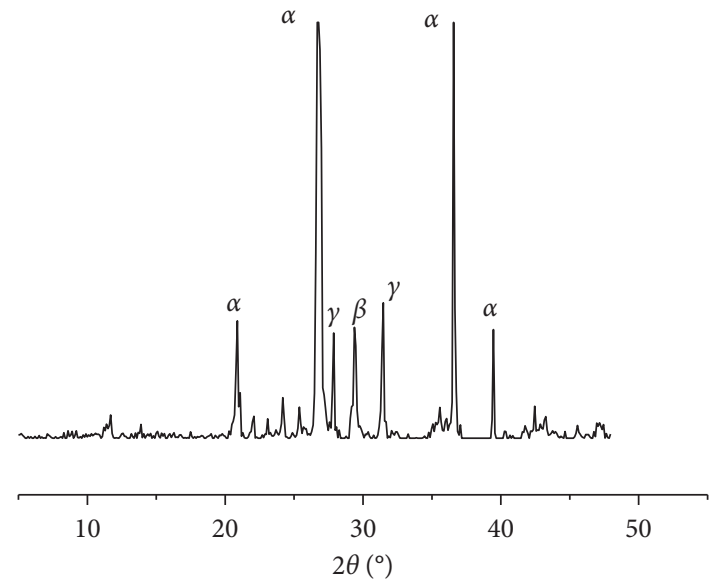

$$
\begin{aligned}
& \alpha-\mathrm{CaCO}_{3} \\
& \beta-\mathrm{SiO}_{2} \\
& \gamma-\mathrm{Ca}_{2}\left(\mathrm{SiO}_{4}\right)
\end{aligned}
$$

FIGURE 5: XRD images of MSWI slag.

As illustrated in Figure 5, the main crystalline substance of slag is $\mathrm{SiO}_{2}$. When the diffraction peaks of $2 \theta$ are $20.8^{\circ}$, $26.7^{\circ}, 36.6^{\circ}$, and $39.5^{\circ}$, the main diffraction peaks are $\mathrm{SiO}_{2}$; 

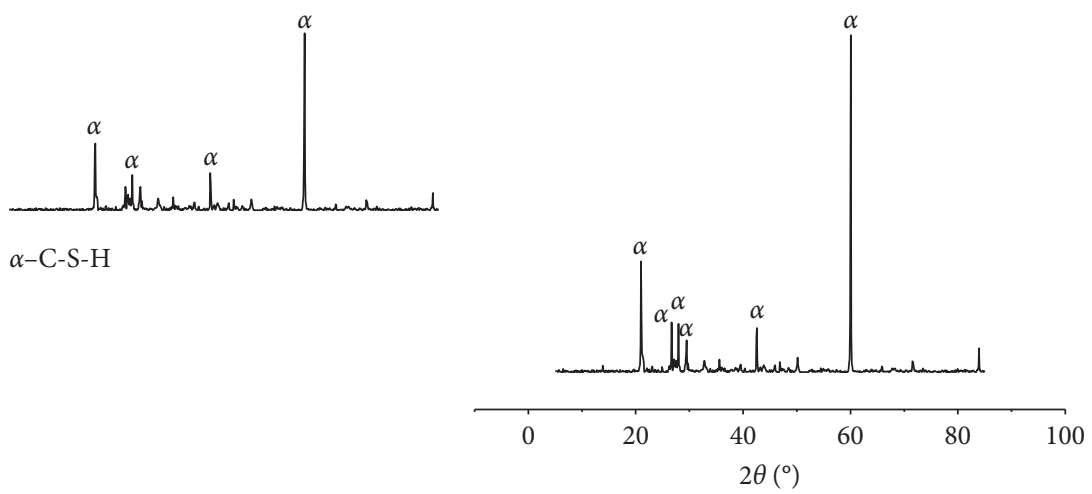

$\alpha-\mathrm{C}-\mathrm{S}-\mathrm{H}$

(a)

(b)

FIgURE 6: XRD spectra of (a) B0C0 and (b) B20C30.

when the diffraction peak of $2 \theta$ is $29.3^{\circ}$, the main diffraction peaks are $\mathrm{CaCO}_{3}$; when the diffraction peaks of $2 \theta$ are $26.8^{\circ}$ and $31.4^{\circ}$, the main diffraction peaks are $\mathrm{CaSiO}_{3}$; when the diffraction peaks of $2 \theta$ are in the range of $10^{\circ}$ to $20^{\circ}$, this indicates that the slag can contain the amorphous materials. Combined with the SEM images of slag, it can be seen that this material has an amorphous geometric structure with a loose and porous surface, which is mainly caused by its forming temperature. The slag particle size is less than $5 \mathrm{~mm}$, and its main components are similar to aggregate; thus, aggregate grading can be improved. Therefore, it is feasible to use slag to partially replace fine aggregate.

In Figure 6, the XRD results of concrete with the mixture ratio of $\mathrm{B} 0 \mathrm{C} 0$ and $\mathrm{B} 20 \mathrm{C} 30$ are compared. The diffraction peaks of $2 \theta$ are $21^{\circ}, 26.8^{\circ}, 28^{\circ}, 42.5^{\circ}$, and $60.1^{\circ}$, and the main diffraction peak is $\mathrm{C}-\mathrm{S}-\mathrm{H}$ (the hydrated calcium silicate). The main peaks of $\mathrm{B} 0 \mathrm{C} 0$ concrete and $\mathrm{B} 20 \mathrm{C} 30$ concrete are concentrated between $20^{\circ}$ and $30^{\circ}$, and the C-S-H generated by B20C30 is essentially the same as the C-S-H generated by B0C0. When $2 \theta=60^{\circ}$, the C-S-H obviously increases. The results illustrate that fly ash and slag are also partially involved in concrete hydration, which is consistent with the strength experiment results.

\section{Conclusions}

By analyzing the compressive strength of concrete mixed with ash and slag at different mixing ratios, the optimum content was determined as fly ash substitution rate of $30 \%$ and slag substitution rate of $20 \%$. After conducting heavy metal leaching tests for fly ash, slag, and B20C30 concrete, it was found that the leaching concentrations of heavy metals (such as $\mathrm{Cu}, \mathrm{Zn}, \mathrm{Cd}, \mathrm{Cr}$, and $\mathrm{Pb}$ ) can decrease with increasing $\mathrm{pH}$. It was also determined that the leaching concentrations of heavy metals are lower than the identification standard for solid waste leaching toxicity. According to characterization tests, the strength of concrete mixed with a certain amount of fly ash and slag was not diminished, and it was found to increase to a certain extent. It is thus feasible to use fly ash to replace cement and slag to replace coarse aggregate. The purpose of this study was to provide theoretical guidance for expanded waste incineration production. However, the present study is still a preliminary study, and more mechanisms should be explored for concrete with different mixing ratios in the future.

\section{Data Availability}

The data used to support the findings of the study are available for the corresponding author upon reasonable request.

\section{Conflicts of Interest}

The authors declare that they have no conflicts of interest.

\section{Acknowledgments}

This work was financially supported by the National Natural Science Foundation of China within the statutory research numbers 51878128, 51708091, 51708267, and 51808101.

\section{References}

[1] National Bureau of Statistics of The People's Republic Of China, China Statistical Yearbook, National Bureau of Statistics of The People's Republic Of China, Beijing, China, 2018.

[2] C. H. K. Lam, A. W. M. Ip, J. P. Barford, and G. McKay, "Use of incineration MSW ash: a review," Sustainability, vol. 2, no. 7, pp. 1943-1968, 2010.

[3] J. M. Chimenos, A. I. Fernández, L. Miralles, M. Segarra, and F. Espiell, "Short-term natural weathering of MSWI bottom ash as a function of particle size," Waste Management, vol. 23, no. 10 , pp. 887-895, f, 2003.

[4] A. Polettini, R. Pomi, P. Sirini, and F. Testa, "Properties of Portland cement - stabilised MSWI fly ashes," Journal of Hazardous Materials, vol. 88, no. 1, pp. 123-138, 2001.

[5] C. Ferreira, A. Ribeiro, and L. Ottosen, "Possible applications for municipal solid waste fly ash," Journal of Hazardous Materials, vol. 96, no. 2-3, pp. 201-216, 2003.

[6] S. Wan, X. Zhou, M. Zhou et al., "Hydration characteristics and modeling of ternary system of municipal solid wastes 
incineration fly ash-blast furnace slag-cement," Construction and Building Materials, vol. 180, pp. 154-166, 2018.

[7] R. Siddique, "Use of municipal solid waste ash in concrete," Resources, Conservation and Recycling, vol. 55, no. 2, pp. 83-91, 2010.

[8] M. J. Quina, J. C. Bordado, and R. M. Quinta-Ferreira, "Treatment and use of air pollution control residues from MSW incineration: an overview," Waste Management, vol. 28, no. 11, pp. 2097-2121, 2008.

[9] F. Colangelo, F. Messina, and R. Cioffi, "Recycling of MSWI fly ash by means of cementitious double step cold bonding pelletization: technological assessment for the production of lightweight Artificial aggregates," Journal of Hazardous Materials, vol. 299, pp. 181-191, 2015.

[10] G. Baykal and A. G. Döven, "Utilization of fly ash by pelletization process; theory, application areas and research results," Resources, Conservation and Recycling, vol. 30, no. 1, pp. 59-77, 2000.

[11] C. Collivignarelli and S. Sorlini, "Reuse of municipal solid wastes incineration fly ashes in concrete mixtures," Waste Management, vol. 22, no. 8, pp. 909-912, 2002.

[12] L. Bertolini, M. Carsana, D. Cassago, A. Quadrio Curzio, and M. Collepardi, "MSWI ashes as mineral additions in concrete," Cement and Concrete Research, vol. 34, no. 10, pp. 1899-1906, 2004.

[13] J. Aubert, B. Husson, and N. Sarramone, "Utilization of municipal solid waste incineration (MSWI) fly ash in blended cementPart 1: processing and characterization of MSWI fly ash," Journal of Hazardous Materials, vol. 136, no. 3, pp. 624-631, 2006.

[14] J. E. Aubert, B. Husson, and A. Vaquier, "Use of municipal solid waste incineration fly ash in concrete," Cement and Concrete Research, vol. 34, no. 6, pp. 957-963, 2000.

[15] J. E. Aubert, B. Husson, and A. Vaquier, "Metallic aluminum in MSWI fly ash: quantification and influence on the properties of cement-based products," Waste Management, vol. 24, no. 6, pp. 589-596, 2000.

[16] R. Cioffi, F. Colangelo, F. Montagnaro, and L. Santoro, "Manufacture of artificial aggregate using MSWI bottom ash," Waste Management, vol. 31, no. 2, pp. 281-288, 2011.

[17] V. Albino, R. Cioff, L. Santoro, and G. L. Valenti, "Stabilization of residue containing heavy metals by means of matrices generating calcium trisulphoaluminate and silicate hydrates," Waste Management \& Research, vol. 14, no. 1, pp. 29-41, 1996.

[18] X. C. Qiao, B. R. Ng, M. Tyrer, C. S. Poon, and C. R. Cheeseman, "Production of lightweight concrete using incinerator bottom ash," Construction and Building Materials, vol. 22, no. 4, pp. 473-480, 2008.

[19] T. Mangialardi, "Sintering of MSW fly ash for reuse as a concrete aggregate," Journal of Hazardous Materials, vol. 87, no. 2, pp. 225-239, 2001.

[20] G. C. A. E. Sebastian and Construction and building materials, Construction and Building Materials, vol. 15, no. 8, pp. 465471, 2001.

[21] M. Y. Way, K. Y. Liu, T. H. Tsai, and J. T. Chou, "Thermal treatment of the fly ash from municipal solid waste incinerator with rotary kiln," Journal of Hazardous Materials, vol. 137, no. 2, pp. 981-989, 2006.

[22] K. Wang, K. Chiang, J. Perng, and C. Sun, "The characteristics study on sintering of municipal solid waste incinerator ashes," Journal of Hazardous Materials, vol. 59, no. 2-3, pp. 201-210, 1998.
[23] Q. X. Zhao, W. Sun, and C. W. Liao, "Effect and echanism of interaction between fly ash proportion and water-binder ratio on the creep characteristics of high perform and concrete," China Civil Eigineering Journal, vol. 12, pp. 76-82, 2009.

[24] B. Zhang, X. Y. Yang, F. C. Sun et al., "Thermal stability of heavy metals in MSWI fly ash using phosphate via water washing pretreatment," Journal of Building Materials, vol. 12, no. 2, pp. 181-185, 2009.

[25] Y. Ménard, A. Asthana, F. Patisson et al., "Thermodynamic study of heavy metals behaviour during municipal waste incineration," Process Safety \& Environmental Protection, vol. 84, no. 4, pp. 290-296, 2009.

[26] W. Chen and J. S. QIian, "Solidification and leaching stability of heavy metals in sintered products made of shale and sewage sludge," Journal of the Chinese Ceramic Society, vol. 40, no. 10, pp. 1420-1426, 2012.

[27] Y. B. Hu, G. Y. Miao, and Y. Xiong, "Mechanical properties and hydration characteristics of concrete subject to subzero temperature condition," Journal of Building Materials, vol. 6, pp. 975-980, 2017.

[28] D. Foti, M. Lerna, M. Sabbà, and V. Vacca, "Mechanical characteristics and water absorption properties of blast-furnace slag concretes with fly ashes or microsilica additions," Applied Sciences, vol. 9, no. 7, p. 1279, 2019.

[29] M. Urs and R. Katrin, "The microstructure of concrete made with municipal waste incinerator bottom ash as an aggregate component," Cement Concrete Research, vol. 36, pp. 14341443, 2006.

[30] P. Patiala, "Review use of municipal solid waste ash in concrete," Resources, Conservation and Recycling, vol. 55, pp. 83-91, 2010. 